\title{
Sistemática de isótopos de oxigênio e carbono aplicada ao estudo da evolução metalogenética do depósito de $\mathrm{Zn}-\mathrm{Pb}$ de Morro Agudo (MG)
}

\author{
Rafael A. Rubo ${ }^{1}$ \& Lena Virgínia Soares Monteiro ${ }^{1}$
}

\begin{abstract}
Resumo A Faixa Vazante-Paracatu representa o distrito mineral responsável por toda a produção de zinco do Brasil. Nessa faixa ocorrem depósitos com tipologias distintas de minério, com predominância de sulfetos (esfalerita, galena, pirita, marcassita), como em Morro Agudo, ou de silicato de zinco, como a willemita, em Vazante. No depósito de $\mathrm{Zn}-\mathrm{Pb}$ de Morro Agudo as rochas hospedeiras (brechas dolomíticas e dolarenitos) apresentam evidências de dolomitização precoce, diagênese marinha, meteórica e de soterramento. Nesse depósito, três episódios de mineralização foram identificados, sendo associados a processos de (1) substituição da rocha hospedeira por esfalerita fina, (2) preenchimento de bolsões e veios por esfalerita, galena, pirita, marcassita, quartzo, dolomita hidrotermal e betume, e (3) formação de veios e vênulas tardios com esfalerita associada a estruturas rúpteis. As assinaturas isotópicas de oxigênio e carbono da dolomita diagenética indicam processos de interação fluido-rocha envolvendo os fluidos mineralizantes. A composição isotópica da dolomita hidrotermal, associada aos sulfetos, indica contribuição de fontes de carbono reduzido à evolução do sistema hidrotermal. Isso sugere a participação de fluidos que interagiram com a unidade argilo-dolomítica estratigraficamente superior aos dolomitos hospedeiros das mineralizações que contém carbono orgânico. Isso implicaria em participação de fluidos hidrotermais descendentes, mais frios e reduzidos, além dos fluidos ascendentes, quentes e metalíferos para a gênese das mineralizações de $\mathrm{Zn}-\mathrm{Pb}$. As composições isotópicas calculadas para os fluidos em equilíbrio com dolomita hidrotermal sugerem que tais fluidos ascendentes e descendentes seriam predominantemente formacionais semelhantes aos associados à gênese de depósitos de $\mathrm{Pb}-\mathrm{Zn}$ do tipo Mississippi Valley.
\end{abstract}

Palavras-chave: depósito de $\mathrm{Zn}-\mathrm{Pb}$, isótopos estáveis, rochas carbonáticas, Grupo Vazante.

\begin{abstract}
Oxygen and carbon isotopic systematic applied to the metallogenetic evolution of the Zn$\mathrm{Pb}$ Morro Agudo deposit, MG, Brazil. The Vazante-Paracatu region represents the mineral district responsible for all the Brazilian zinc production. In this region, mineral deposits are characterized by predominantly sulphide-rich ores (sphalerite, galena, pyrite, marcasite), as in Morro Agudo, and silicatic ores with willemite at Vazante. In the Morro Agudo deposit, the host rocks (dolomitic breccias and dolarenites) have evidence of early dolomitization, besides marine, meteoric and burial diagenesis. Three mineralization episodes have been defined and are associated with processes of (1) replacement of host rock by fine-grained sphalerite, (2) open-space filling in vugs and veins by sphalerite, galena, pyrite, marcasite, quartz, hydrothermal dolomite and bitumen, and (3) formation of late veins and veinlets with sphalerite within brittle structures. The isotopic signatures of the diagenetic dolomite indicate processes of interaction with mineralizing fluids, while the isotopic composition of the hydrothermal dolomite, associated with sulphides, suggests contribution of reduced carbon for the hydrothermal system originated from the stratigraphically upper argilic-dolomitic unit. This could imply in downward flow of cold and reduced fluids in addition to ascendant migration of hot and metalliferous brines during mineralization. The calculated oxygen isotopic compositions for hydrothermal fluids suggest formational origin for the ascendant and descendant fluids similar to those associated to the genesis of Mississippi Valley Type Pb-Zn deposits.
\end{abstract}

Keywords: Morro Agudo, Zn-Pb deposit, stable isotope, dolostone, Vazante Group.

INTRODUÇÃO Mineralizações de zinco e chumbo são conhecidas na região de Paracatu e Vazante, noroeste de Minas Gerais, desde a década de 1950. A partir do final da década seguinte, as principais minas de zinco do país, Morro Agudo e Vazante, entraram em operação, sendo responsáveis ainda hoje por toda a produção de concentrado de zinco brasileira. Esses depósitos ostentam atualmente, após quatro décadas de produção, recursos estimados em 7,9 milhões de toneladas medidas com teor médio de 23,4\% (minério não sulfetado, willemítico de Vazante) e 2,25 milhões de toneladas medidas com 4,55\% de zinco (minério sulfetado de Morro Agudo, Votorantim Metais Zinco 2008).

Os depósitos de zinco de Vazante e Morro Agudo associam-se ao Grupo Vazante (Dardenne et al. 1998), aflorante ao longo da Faixa Vazante-Paracatu, e apresentam características geológicas contrastantes que se refletem nos tipos de minério conhecidos. Em Vazante, a associação de minerais de minério é constituída principalmente por willemita $\left(\mathrm{Zn}_{2} \mathrm{SiO}_{4}\right)$, hematita, 
quartzo, siderita, dolomita, clorita, franklinita e zincita, com esfalerita e galena subordinadas (Monteiro 1997, Monteiro et al. 1998a,b 1999b). Em Morro Agudo e nas demais ocorrências na parte norte da faixa, incluindose os depósitos de Ambrósia e Fagundes, a mineralogia do minério é representada por esfalerita, galena, pirita, dolomita, calcedônia, quartzo e barita.

Apesar da existência de um grande volume de dados geológicos e informações metalogenéticas relativas aos depósitos da Faixa Vazante-Paracatu as relações genéticas entre depósitos sulfetados (Morro Agudo) e não-sulfetados (Vazante) ainda não foram bem estabelecidas (Dardenne 1979, Monteiro 1997, 2002, Monteiro et al. 1999b, 2006, 2007, Cunha 1999, Cunha et al. 2007, Misi et al. 2005). Embora isótopos de oxigênio e carbono tenham sido aplicados ao estudo do depósito de Vazante (Monteiro 1997, 2002, Monteiro et al. 1999b, 2007), estudos semelhantes ainda não haviam sido realizados no depósito de Morro Agudo, dificultando a compreensão dos controles da gênese dos dois tipos distintos de minério conhecidos na região.

Este estudo apresenta resultados relativos à caracterização petrográfica das rochas carbonáticas hospedeiras inalteradas e mineralizadas de Morro Agudo, assim como estudos de isótopos estáveis de oxigênio e carbono em diferentes gerações de minerais carbonáticos, diagenéticos e hidrotermais, associados ao minério de zinco-(chumbo) sulfetado. Esses estudos podem contribuir para a avaliação do papel de fluidos distintos na gênese do depósito e auxiliar na compreensão dos processos genéticos responsáveis pelas mineralizações, sulfetadas e não sulfetadas, associadas ao Grupo Vazante, auxiliando na elaboração de modelos exploratórios e prospectivos.

MÉTODOS Descrições detalhadas e amostragem sistemática foram realizadas tanto em testemunhos de sondagem como em galerias da mina subterrânea de Morro Agudo. Estudos petrográficos em luz transmitida e refletida e de microscopia eletrônica de varredura com EDS (Energy Dispersive X-Ray Spectrometer) acoplado foram realizados no IG - UNICAMP. Após a definição de diferentes gerações de dolomita presentes nas amostras, a separação mineral foi realizada com o auxílio de microretífica com discos diamantados e lupa binocular também no IG - UNICAMP. As análises de isótopos de oxigênio e carbono foram realizadas no Laboratório de Isótopos Estáveis (LABISE) da UFPE, onde a extração do gás $\mathrm{CO}_{2}$ a partir das amostras foi feita em linha de alto vácuo após reação com ácido ortofosfórico $\left(\mathrm{H}_{3} \mathrm{PO}_{4}\right)$ a $25^{\circ} \mathrm{C}$ por três dias. $\mathrm{O} \mathrm{CO}_{2}$ liberado foi purificado criogenicamente e analisado em espectrômetro de massa SIRA II. Os resultados foram reportados na notação usual $\delta$ em permil (\%o) em relação ao padrão internacional PDB (Pee Dee Belemnite) e os dados isotópicos de oxigênio foram também convertidos ao padrão SMOW (Standard Mean Ocean Water). Incertezas nas medidas isotópicas foram estimadas como menores que $0,1 \%$ para carbono e $0,2 \%$ para oxigênio com base em análises múltiplas do padrão interno do laboratório (BSC).
CONTEXTO GEOLÓGICO O Grupo Vazante (Figs. 1 e 2), definido por Dardenne et al. (1998) e Dardenne (2001), hospeda as mineralizações de zinco e chumbo enfocadas neste estudo. Esse grupo representa uma das unidades metassedimentares do segmento sul da Faixa de Dobramentos Brasília (Almeida 1967) inseridas em um complexo sistema de nappes e falhas de empurrão com vergência para o Cráton do São Francisco.

O Grupo Vazante (Dardenne et al. 1998) é constituído por uma espessa sequência marinha pelítico-carbonática aflorante em uma faixa N-S de aproximadamente $200 \mathrm{~km}$, em contato tectônico com os grupos Canastra, a oeste, e Bambuí, a leste. Na base predominam metaconglomerados, quartzitos e diamictitos (Formação Santo Antônio do Bonito), cujos protólitos foram depositados em ambiente glacio-marinho de águas relativamente profundas (Dardenne et al. 1998). Estes litotipos gradam para metarritmitos e metapelitos carbonáticos que hospedam depósitos de fosfato (Formação Rocinha) e unidades metapsamo-pelíticas da Formação Lagamar.

Em direção ao topo da sequência ocorrem pacotes de ardósias com lentes de quartzitos (Formação Serra do Garrote), que são sobrepostos por unidades predominantemente dolomíticas representadas pela Formação Serra do Poço Verde (subdividida nos membros Morro do Pinheiro Inferior, Morro do Pinheiro Superior, Pamplona Inferior e Pamplona Médio) e pela Formação Morro do Calcário (Membro Pamplona Superior), que hospedam as mineralizações de zinco e chumbo. No topo desta associação ocorrem filitos, metassiltitos carbonáticos, lentes de metadolomitos e leitos quartzíticos da Formação Lapa, Membro Serra do Velosinho (Dardenne et al. 1998, Dardenne 2001).

Mina de Morro Agudo O depósito de Morro Agudo (Fig. 3) é hospedado por rochas dolomíticas do Grupo Vazante (Formação Morro do Calcário, Membro Pamplona Superior, Dardenne et al. 1988), que constituem uma unidade clástica com granodecrescência ascendente. Na base da unidade, predominam brechas dolomíticas que gradam para brechas dolareníticas, constituídas por fragmentos de dolomitos laminados e maciços em matriz dolarenítica. Acima das brechas, ocorrem dolarenitos com interdigitações de filitos pretos carbonosos com pirita disseminada (Madalosso \& Valle 1978, Romagna \& Costa 1988).

As unidades dolomíticas foram interpretadas como associadas à fácies de pós-recife (back-reef) situada no flanco oeste do bioherma estromatolítico do Morro do Calcário (Dardenne 1979, Madalosso \& Valle 1978, Madalosso 1980, Bez 1980), enquanto os filitos carbonosos representariam uma unidade depositada a oeste do recife, em ambiente lagunar, mais restrito, que pode ser correlacionada à unidade basal da Formação Serra da Lapa (Romagna \& Costa 1988).

Os corpos de minério de Morro Agudo são balizados por uma falha com atitude N350/75SW, que faz parte de um sistema de falhas normais pouco espaçadas que interceptam os corpos mineralizados (Romagna \& 


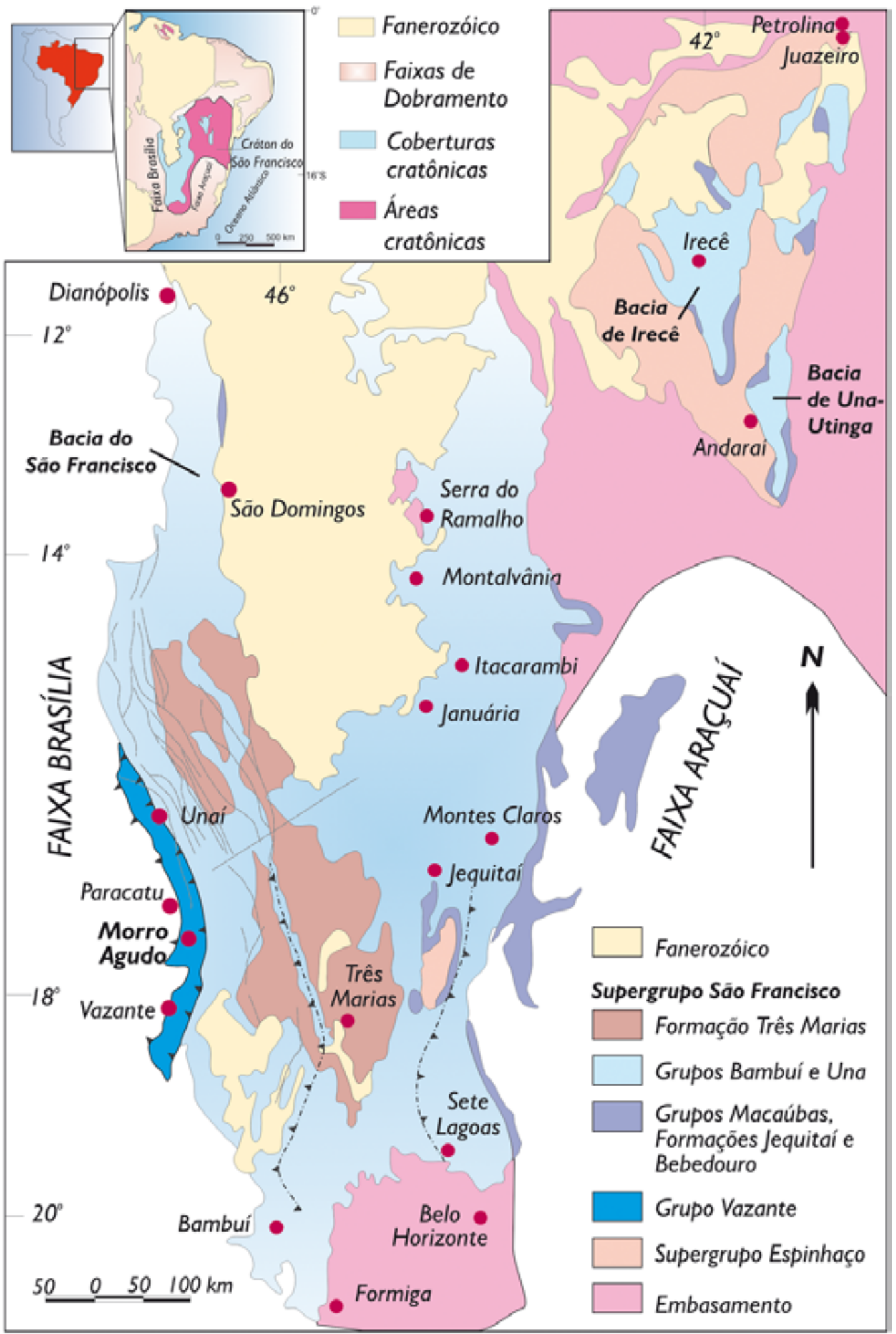

Figura 1 - Mapa geológico simplificado da Bacia do São Francisco, mostrando a área de ocorrência do Grupo Vazante, hospedeiro das mineralizações de Zn-Pb. Modificado de Alkmim \& Marshak (1998) e Misi (2001).

Costa 1988). Tais corpos são restritos à zona de capa em relação à falha (Romagna \& Costa 1988).

Os corpos de minério $(\mathrm{G}, \mathrm{H}, \mathrm{I}, \mathrm{J}, \mathrm{K}, \mathrm{L}, \mathrm{M}$ e N ; Fig. 3), seguem, segundo Oliveira (1998), a tendência das rochas hospedeiras, sendo mais espessos na base (G) para o topo $(\mathrm{N})$. As características dos principais corpos são descritas a seguir.

Corpos GHI: corpos basais hospedados por bre- 

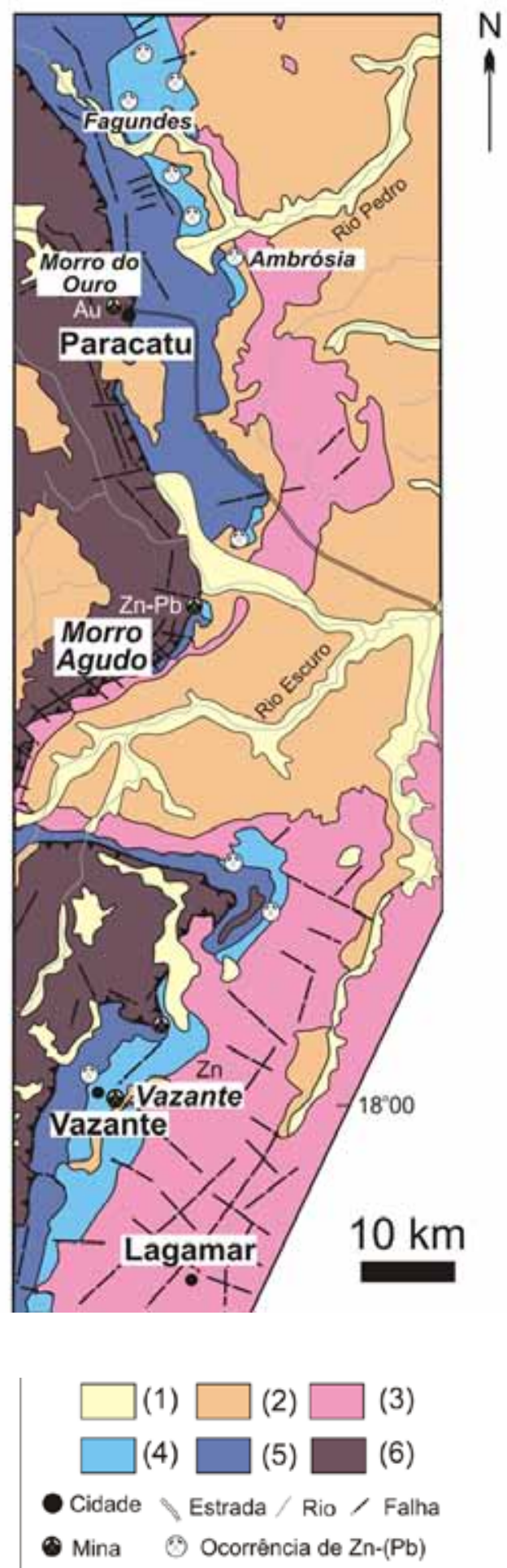

Figura 2 - Mapa geológico simplificado da Faixa Vazante-Paracatu mostrando a localização da Mina de $\mathrm{Zn}-\mathrm{Pb}$ de Morro Agudo (Votorantim Metais Zinco). (1) Depósitos aluvionares; (2) Depósitos coluvionares e eluvionares; (3-5) Grupo Vazante: (3) Formação Serra do Garrote; (4) Formações Morro do Calcário e Serra do Poço Verde; (5) Formação Lapa; (6) Grupo Canastra, Formação Paracatu. chas dolomíticas intraformacionais (doloruditos) contendo clastos angulares e blocos de dolomitos, incluindo clastos do Corpo N (Cunha et al. 2007), cimentados por esfalerita e galena.

Corpos JKL: hospedados por dolomitos oolíticos que apresentam cimentação por sulfetos (principalmente esfalerita) de granulometria fina a grossa. Os oólitos são dolomitizados e parcialmente preservados de uma posterior silicificação (Cunha et al. 2007).

Corpo M: composto por galena e esfalerita de granulometria grossa formando veios irregulares em dolarenitos no topo da Formação Morro do Calcário.

Corpo N: composto por sulfetos de granulometria fina, constitui corpo stratabound, sendo hospedado por unidades dolareníticas intercaladas aos filitos pretos carbonosos no topo da Formação Morro do Calcário. Laminações alternadas de chert, galena, esfalerita e pirita e a presença de camadas milimétricas de esfalerita muito fina e nódulos de sílica e sulfetos sugerem uma origem singenética ou sin-diagenética para este corpo (Misi et al. 2005).

Em Morro Agudo a mineralização tem sido considerada como sin-diagenética (Dardenne 1979, Bez 1980, Dresch 1987, Romagna \& Costa 1988, Dardenne \& Freitas-Silva 1999, Cunha 1999, Misi et al. 1999), mas as texturas dos sulfetos são também indicativas de episódios de mineralização durante os estágios tardi-diagenéticos e epigenéticos da evolução do Grupo Vazante (Dardenne 1979, Dardenne \& Schobbenhaus 2000).

Estudos isotópicos de chumbo realizados por Cunha et al. (2007) no depósito de Morro Agudo indicaram que: (1) a galena do corpo N, que apresentou razões de chumbo radiogênico menores, foi formada durante estágios iniciais da mineralização, (2) as maiores razões de chumbo radiogênico dos corpos GHI, JKL e M são devidas a uma mistura incompleta de chumbo de pelo menos duas fontes, sendo ambas provavelmente relacionadas à crosta superior. Dessa forma, apenas o minério do corpo $\mathrm{N}$ seria sin-diagenético, enquanto que o minério dos outros corpos seriam epigenéticos.

\section{RESULTADOS}

Caracterização das rochas hospedeiras $\mathrm{Na}$ base do depósito de Morro Agudo ocorre uma unidade de brechas dolomíticas (doloruditos) de cor cinza com clastos angulosos a sub-arredondados milimétricos a métricos $(>1 \mathrm{~m})$ em matriz dolarenítica (Fig. 4a). Segundo a classificação de Dunhan (1962) tratam-se de rudstones, pois parte das brechas são suportadas por componentes maiores que 2 milímetros e de floatstones pois podem ser também suportadas pela matriz.

A brecha apresenta clastos de dolomicritos $(\mathrm{mu}$ dstones e wackestones) e dolomitos com laminações resultantes da atividade de ciano-bactérias (bindstones), assim como dolomitos com estruturas estromatolíticas (framestones), que também são observadas na unidade estratigraficamente superior. Alguns dos clastos também são de brechas, sugerindo recorrência da brechação.

Tal recorrência torna-se clara devido à presença de intraclastos arredondados, geralmente microesparíti- 


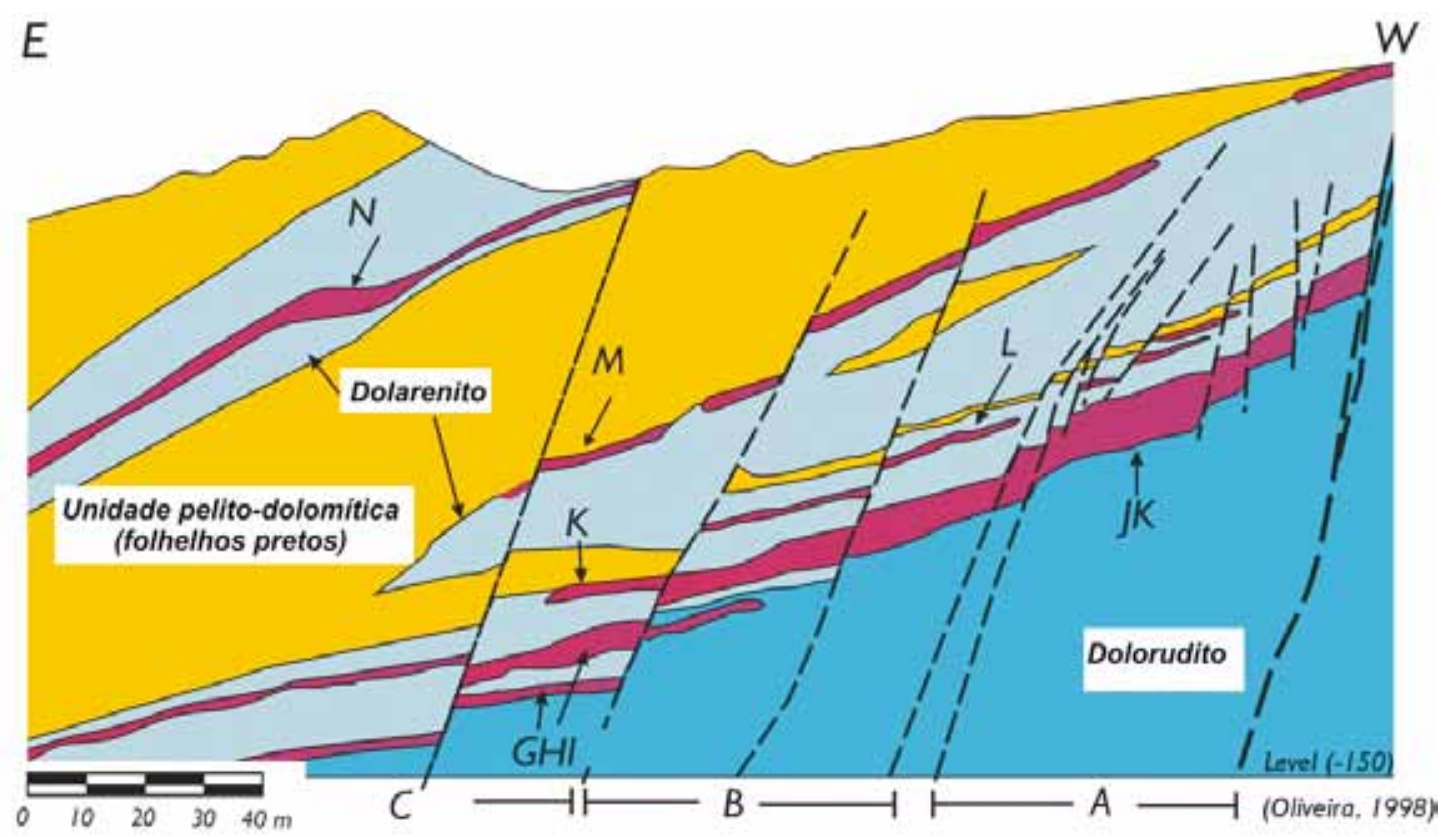

Figura 3 - Perfil geológico do depósito de Morro Agudo (Oliveira 1998).

cos, que ocorrem dentro de outros clastos maiores, mais angulosos, presentes nas brechas. Os clastos maiores estão imersos em uma matriz também esparítica, apresentando granulometria um pouco maior do que a dos clastos, evidenciando uma fase de cimentação meteórica durante a diagênese. Outros clastos arredondados pisolíticos, micríticos, ocorrem na matriz esparítica fora dos clastos angulosos pisolíticos a oncolíticos esparíticos.

Evidências de silicificação podem ser observadas nas brechas basais, nas quais calcedônia substitui parcialmente os intraclastos. A substituição por calcedônia é mais comum nos clastos mais angulosos e em suas bordas internas.

Em alguns testemunhos de sondagem, foram observados, interdigitada a essa unidade basal, brecha suportada por matriz rica em matéria orgânica e argilo-minerais.

Estratigraficamente acima dos doluruditos ocorrem dolarenitos de cor cinza que representam a principal unidade hospedeira da mineralização de zinco e chumbo de Morro Agudo. Comumente, os dolarenitos apresentam oólitos, oóides, pisóides e oncóides imersos na matriz dolarenítica, assim como uma grande variedade de intraclastos (Figs. $5 \mathrm{a}$ e $5 \mathrm{~b}$ ). Os intraclastos apresentam tamanhos variados, de 0,4 a 2 milímetros de diâmetro, e são arredondados, indicando que foram submetidos à retrabalhamento. Comumente, apresentam laminação por ciano-bactérias e estruturas estromatolíticas e partículas carbonáticas que podem ser bem preservadas ou obliteradas por recristalização.

Os dolarenitos apresentam matriz micrítica ou microesparítica/esparítica resultante de substituição neomórfica de uma fase inicial de micrito. Essa matriz também é localmente substituída por calcedônia.

Em alguns casos, as partículas carbonáticas são substituídas por dolomita esparítica. Nesses casos, relí- quias das texturas sedimentares e mesmo a morfologia das partículas carbonáticas tornam-se menos evidentes. Localmente, tais partículas carbonáticas ocorrem como "fantasmas", nas quais apenas o contorno mais escuro destaca-se em meio ao cimento esparítico. Calcedônia também pode substituir as partículas carbonáticas devido à silicificação. Essa substituição ocorre inicialmente ao longo das laminações (como nas lâminas concêntricas de oólitos, por exemplo) até a substituição completa da partícula carbonática.

Também são comuns nos dolarenitos superfícies estilolíticas. Ao longo dessas superfícies, comumente ocorrem fases minerais diferentes das que ocorrem na matriz do dolarenito, tais como sulfetos. Em alguns casos, os estilólitos delimitam diferentes clastos nas brechas, que se assemelham a brechas estilolíticas (stylolitic breccias). Veios milimétricos a centimétricos de dolomita esparítica geralmente são paralelos às superfícies estilolíticas, enquanto vênulas de calcedônia e de dolomita esparítica cortam os veios maiores perpendicularmente às superfícies estilolíticas.

Ocorre ainda no depósito de Morro Agudo, estratigraficamente acima das unidades predominantemente dolomíticas, uma unidade argilo-dolomítica, localmente interdigitada aos dolarenitos, que hospedam o corpo N. Esse litotipo, bastante fino apresenta coloração cinza escura devido à presença de matéria orgânica e encontra-se finamente laminado. Podem ser classificados como mudstones (Dunhan 1962), pois se tratam de rochas carbonáticas argilosas e carbonosas com menos de $10 \%$ de componentes aloquímicos. Associadas a tais rochas podem também ser reconhecidas margas e filitos pretos carbonosos. Foi observado localmente, em testemunhos de sondagem, contato tectônico entre as rochas argilo-dolomíticas e o dolarenito. 

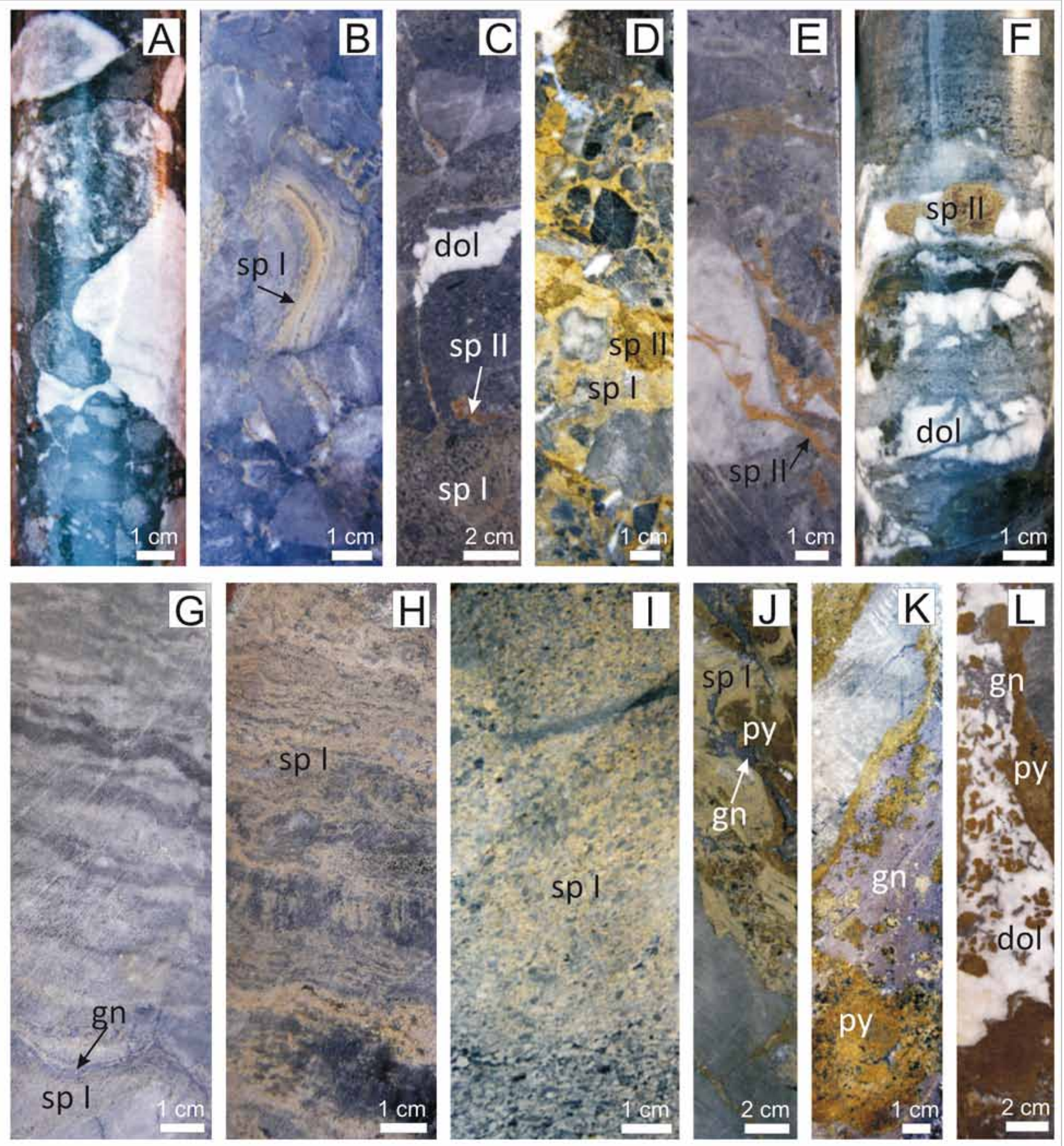

Figura 4 - Testemunhos de sondagem da Mina de Morro Agudo. (A) Dolorudito não mineralizado; (B) Dolorudito com clastos de dolomito estromatolítico parcialmente substituido por esfalerita fina; (C) Dolorudito com clastos falhados (topo). Esfalerita fina (sp I) substitui clastos e matriz dolarenitica (parte de baixo), enquanto esfalerita mais grossa (sp II) e dolomita esparítica grossa preenchem espaços abertos e fraturas; (D) Dolorudito mineralizado no qual a esfalerita ocorre principalmente substituindo a matriz; (E) Esfalerita associada a vênulas que cortam clastos e matriz em dolorudito; (F) Dolomita branca esparítica e esfalerita grossa (sp II) preenchendo espaços abertos; (G) Dolomito com laminação por ciano-bactérias fracamente mineralizado; (H) Dolomito com laminação por ciano-bactérias substituído por esfalerita fina ao longo da laminação; (I) Dolarenito mineralizado com matriz substituída por esfalerita fina; (J) Pirita, esfalerita e galena em zona de substituição em dolarenito; (K) Galena e pirita em dolomito; (L) Associação de dolomita branca esparítica, pirita e galena preenchendo espaços abertos em dolomito. Abreviações: sp = esfalerita; dol = dolomita; $g n=$ galena; py = pirita . 

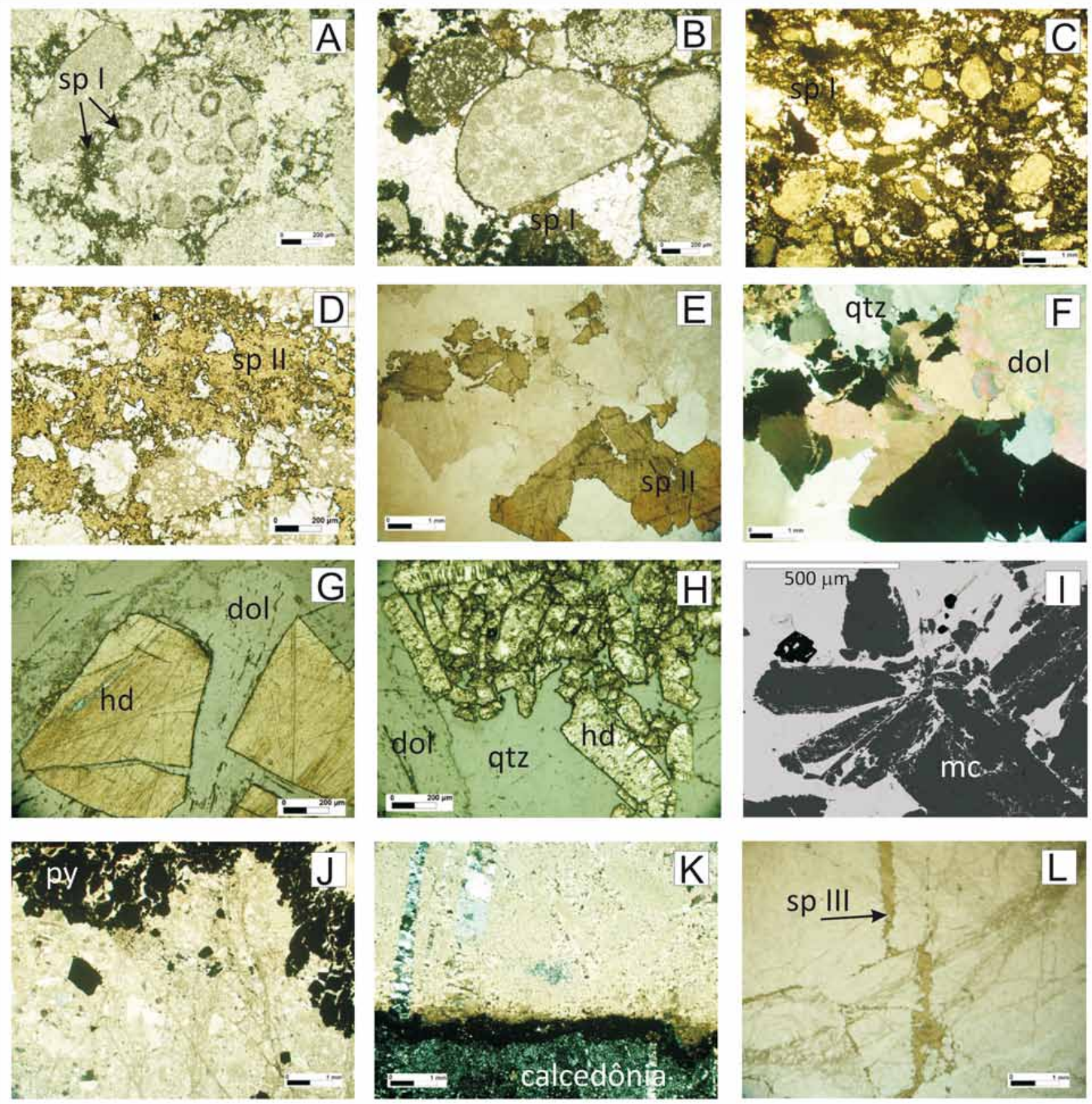

Figura 5 - Fotomicrografias de amostras mineralizadas do depósito de Morro Agudo. (A) Dolarenito com esfalerita fina entre intraclastos e substituindo partículas carbonáticas em clasto (luz transmitida, polarizadores descruzados); (B) Esfalerita fina (sp I) nas bordas de intraclastos, que também são seletivamente substituídos (lado esquerdo superior; luz transmitida, polarizadores descruzados); (C) Dolarenito mineralizado; (D) Esfalerita grossa substituindo dolarenito (luz transmitida, polarizadores descruzados); (E) Cristais de esfalerita (sp II) zonados associados a quartzo e dolomita esparítica com texturas de preenchimento de espaços abertos (luz transmitida, polarizadores descruzados); (F) Idem com polarizadores cruzados; (G) Hidrocarbonetos sólidos (betume) associado a dolomita esparítica (luz refletida); (H) Hidrocarbonetos sólidos (betume) associado a dolomita esparítica e quartzo (luz refletida); (I) Cristais de marcassita associados a esfalerita (imagem de elétrons retro-espalhados); (J) Dolomito recristalizado e fraturado, parcialmente substituído por pirita (Luz transmitida, polarizadores descruzados); (K) Dolomito parcialmente substituido por calcedônia (parte inferior da foto; luz transmitida, polarizadores cruzados); (L) Vênulas tardias de esfalerita associadas a sistema de fraturas e microfalhas (luz transmitida, polarizadores descruzados). Abreviações: $s p=$ esfalerita; dol = dolomita; $h d=$ hidrocarboneto sólido; $m c=$ marcassita; $p y=$ pirita . 


\section{Caracterização das rochas mineralizadas}

CORPO GHI Nas brechas basais podem ser reconhecidos ao menos dois estágios de mineralização. Um estágio inicial é representado por esfalerita fina que ocorre preferencialmente ao longo da laminação em clastos de dolomitos laminados (esteiras; Fig. 4b), indicando um estágio de mineralização anterior à brechação ou substituição seletiva do clasto devido à sua maior porosidade. Esfalerita fina também substitui localmente tanto clastos como a matriz dolarenítica dos doloruditos (Fig. 4c).

O estágio principal, no entanto, é representado por esfalerita, galena e pirita, que ocorrem como cristais grossos principalmente nas bordas dos intraclastos (Fig. 4d), como preenchimentos de espaços abertos, veios e cavidades (Fig. 4f) ou ao longo de superfícies estilolíticas nos corpos de minério designados como GHI. Dolomita branca esparítica, quartzo, calcedônia e hidrocarbonetos sólidos comumente ocorrem associados aos sulfetos grossos.

Diversas texturas do minério observadas ao microscópio em luz transmitida e refletida foram interpretadas como de preenchimento de espaços vazios, devido ao crescimento dos cristais com faces cristalinas bem desenvolvidas perpendicularmente às paredes da cavidade (textura em pente ou comb). Na maioria dos casos, a dolomita esparítica é o mineral que ocorre mais próximo às bordas dos veios e cavidades, assim como o quartzo e a calcedônia, que ocorrem em menor quantidade. Os sulfetos tendem a ocorrer nas regiões mais centrais. Outras texturas características do minério incluem zonas de crescimento em sulfetos e texturas coloformes, e de múltiplas bandas monominerálicas intercaladas. Essas bandas originam veios simétricos e rítmicos, que por vezes apresentam-se brechados.

Com o auxílio do microscópio eletrônico de varredura (MEV) foi possível a visualização de texturas coloformes rítimicas com alternância entre pirita e esfalerita, indicativas de cristalização rápida. Outros atributos e texturas observadas também indicam cristalização rápida das fases minerais, como a presença de uma textura dendrítica e de porosidade nos sulfetos. Em muitas ocasiões, os cristais de pirita apresentam inclusões de material carbonático, apatita, calcedônia ou quartzo nas partes centrais dos cristais e sobrecrescimento subédrico nas bordas, indicando a ocorrência de rápida cristalização em um período inicial de deposição do sulfeto sucedido por um período de cristalização mais lento.

A esfalerita de granulometria média a grossa pode apresentar um gradiente de tonalidades de sua coloração amarronada (Fig. 5e), apresentando bordas com maior conteúdo de ferro, como comprovado por análises de EDS. Texturas de zoneamento também foram observadas em dolomita hidrotermal, que apresenta alternância de zonas mais claras relacionadas à menor quantidade de ferro e mais escuras com maior conteúdo de ferro no sistema.

Vênulas tardias com esfalerita fina também podem ser observadas no Corpo GHI (Fig. 4e).

CORPO JKL Nos dolomitos laminados (Figs. 4g e 4h) e nos dolarenitos (Fig. 4i), foram observadas diversas texturas interpretadas como de substituição a partir de dissolução de fases minerais e subsequente reprecipitação. Na maioria dos casos a identificação de tais texturas é simples, pois as fases minerais substituídas encontram-se ainda parcialmente presentes. Uma primeira geração de esfalerita muito fina, com galena e pirita subordinadas (Fig. 4j), substitui o dolarenito, conferindo coloração amarelada a ocre à rocha. Intervalos nos quais a substituição por esfalerita foi generalizada correspondem ao minério de mais alto teor da Mina de Morro Agudo.

A substituição dos dolarenitos pode ser seletiva, ao longo dos contatos entre partículas carbonáticas ou intraclastos (Figs. 5a e 5b). Comumente, algumas partículas são mais intensamente substituídas por esfalerita em relação a outras presentes na mesma amostra. Em intervalos fortemente mineralizados, cimentos diagenéticos e matriz também são substituídos por esfalerita (Fig. 5c).

A substituição da rocha por sulfetos também pode ser observada em dolarenitos intensamente silicificados (substituídos por calcedônia; Fig. 5k). Nesses são observados cristais de dolomita esparítica e de pirita associados, além de galena e esfalerita em quantidades menores, sendo que, em alguns casos, a pirita substitui quase que completamente toda a rocha.

Nas zonas mineralizadas, é comumente observada marcassita com hábito tabular (Fig. 5i) ou em arranjos radiados. Cristais de pirita com hábito semelhante também foram observados e podem representar pseudomorfos, formados a partir da marcassita inicial.

Os dolarenitos apresentam ainda veios e bolsões preenchidos por uma segunda geração de esfalerita mais grossa e marrom (Fig. 5d), além de galena e pirita (Fig. 5j). Galena e pirita predominam localmente (Fig. $4 \mathrm{k})$. Nesses veios ou bolsões, os sulfetos ocorrem associados a dolomita branca esparítica (Fig. 41, 5e e 5f), quartzo, calcita, fluorita, barita e material preto e rugoso, que o uso de MEV confirmou tratar-se de um hidrocarboneto sólido (Figs. 5g e 5h). Esses hidrocarbonetos sólidos ocorrem das mais diversas formas, sendo muito comum sua ocorrência com hábito tabular. Essa forma tabular assemelha-se muito à observada na marcassita $\mathrm{e}$ pirita, o que poderia indicar que tanto a pirita quanto o hidrocarboneto sólido podem ter substituído uma mesma fase mineral. Os hidrocarbonetos sólidos comumente ocorrem nas bordas dos cristais de dolomita.

Nos veios e bolsões, a segunda geração de esfalerita apresenta texturas de preenchimento de espaços abertos, típica de mineralização epigenética. Esses bolsões de preenchimento não são limitados à unidade dolarenítica, mas ocorrem em todo o depósito, ora em maior e ora em menor quantidade e tamanho, representando o minério principal nas brechas basais (unidade dolorudítica).

Foram observadas microfraturas e microfalhas com espessuras variáveis. A maioria parece estar relacionada a um evento tardio. Em alguns casos essas microfalhas cortam e deslocam levemente veios e vênulas. Entretanto, em outros, a mineralização epigenética representada por esfalerita de granulometria média, 
galena e pirita, passa a aproveitar essas estruturas ocorrendo associadas a elas (Fig. 51).

Estilólitos também delimitam zonas de ocorrência de esfalerita média a grossa. Este mineral ocorre nas proximidades da superfície estilolítica ou até alguns milímetros dessa. Essa geração de esfalerita média a grossa ocorre também nos espaços intercolunares em estromatólitos e parece ser a mesma geração de esfalerita média encontrada em cavidades e veios. Em menor quantidade, associada a esta esfalerita, é comum a ocorrência de galena.

Corpo $N$ A esfalerita observada no corpo $\mathrm{N}$ apresenta granulometria média, semelhante à esfalerita comumente observada em veios e vugs. Esse mineral, assim como a galena subordinada, ocorre associado com calcedônia ou dolomita esparítica. As zonas mineralizadas nesse corpo parecem apresentar uma orientação concordante com a laminação da rocha hospedeira. Entretanto, ao longo dessa estrutura a esfalerita ocorre em um sistema de vênulas.

Mineralização nos filitos grafitosos Sulfetos de granulometria grossa, principalmente pirita, e dolomita branca esparítica ocorrem em veios milimétricos a centimétricos, acompanhando ou não a laminação dos filitos e marga. A pirita geralmente ocorre concordante à laminação e é o sulfeto mais abundante desta unidade. Esfalerita grossa e dolomita esparítica ocorrem principalmente em bolsões de preenchimento, que são menos frequentes.

Ocasionalmente, associado a esses veios e bolsões de preenchimento, ocorre novamente o hidrocarboneto sólido, também observado nas outras unidades. Geralmente ele ocorre associado à dolomita esparítica e a esfalerita média a grossa.

Gerações de dolomita diagenéticas e hidrotermais Diferentes gerações de dolomita foram caracterizadas nesse estudo: (I) dolomicrito, que representa a geração mais antiga de dolomita e que constitui o dolomito hospedeiro mais preservado das alterações pósdeposicionais, (IIa) dolomita microesparítica possivelmente relacionada ao neomorfismo e diagênese inicial, (IIb) dolomita com hábito tabular, possivelmente representando pseudomorfos de sulfatos evaporíticos, (III) dolomita esparítica, hidrotermal, que ocorre como preenchimento de veios e cavidades, e (IV) dolomita esparítica em grandes cristais, apresentando texturas típicas de preenchimento de espaços vazios e veios, comumente associada com esfalerita grossa e galena, representando o principal mineral de ganga desse depósito.

Outra geração de dolomita, considerada diagenética, foi também observada apenas localmente, tal como dolomita fibrosa na borda de cavidades e laminações nos estromatólitos, que poderiam ser resultantes de diagênese marinha.

\section{Isótopos Estáveis}

COMPOSIÇÃO ISÓTOPICA DE C E O EM DOLO-

MITA Análises de isótopos estáveis de carbono e oxigênio foram realizadas em diferentes gerações de dolomita (I, IIb, III e IV, Tab. 1). Os resultados obtidos, apresentados na tabela 2 , foram analisados e comparados com outros resultados disponíveis na literatura para depósitos da Faixa Vazante-Paracatu (Monteiro 1997, Monteiro et al. 1999a, Azmy et al. 2001, Monteiro 2002).

A dolomita classificada como do tipo I, que constitui 80 a $90 \%$ das rochas hospedeiras preservadas, apresenta valores de $\delta^{18} \mathrm{O}$ entre $+26,97 \%$ e $+19,65 \%$ e de $\delta^{13} \mathrm{C}$ entre $+0,49 \%$ e $-0,60 \%$. $\mathrm{O}$ mais baixo valor de $\delta^{13} \mathrm{C}$ representa um outlier, com composição semelhante a da dolomita hidrotermal (III e IV; Fig. 6). Esse valor refere-se a uma amostra descrita como dolomita micrítica parcialmente preservada em rocha silicificada. Os valores encontrados para esta amostra são condizentes com essa descrição, refletindo possivelmente reequilíbrio isotópico devido à interação com fluidos hidrotermais. Se esta amostra não fosse considerada, o valor mais baixo de $\delta^{13} \mathrm{C}$ obtido seria de $+0,25 \%$. O gráfico $\delta^{18} \mathrm{O}$ vs. $\delta^{13} \mathrm{C}$ mostra uma tendência definida por uma maior variação dos valores de $\delta^{18} \mathrm{O}$ para a dolomita do tipo I e por pequeno intervalo de variação de $\delta^{13} \mathrm{C}$.

Para a dolomita tabular do tipo IIb, foi analisada apenas uma amostra que apresentou valor de $\delta^{18} \mathrm{O}$ igual a $+26,66 \%$ e de $\delta^{13} \mathrm{C}$ de $+1,78 \%$. Estes valores diferem bastante dos demais encontrados para o depósito, o que evidencia trata-se, de fato, de uma geração diferente de dolomita com o valor mais alto de $\delta^{13} \mathrm{C}$ encontrado para o depósito.

A dolomita esparítica hidrotermal classificada como do tipo III apresenta valores de $\delta^{18} \mathrm{O}$ entre $+22,75 \%$ $\mathrm{e}+15,52 \%$ e de $\delta^{13} \mathrm{C}$ entre $+0,95 \%$ e $-1,16 \%$. O menor valor de $\delta^{13} \mathrm{C}$ refere-se à amostra do Corpo $\mathrm{N}$, localizado próximo ao filitos carbonosos. Essa geração de dolomita III apresenta as maiores variações de $\delta^{13} \mathrm{C}$ observadas, que podem ser relacionadas a um intervalo amplo de $\delta^{18} \mathrm{O}$. Tais composições definem uma tendência de covariância isotópica negativa, na qual os maiores valores de $\delta^{18} \mathrm{O}$ correspondem aos menores de $\delta^{13} \mathrm{C}$ (Fig. 6).

A dolomita IV, que comumente ocorre associada à esfalerita mais grossa, apresenta valores de $\delta^{18} \mathrm{O}$ entre $+18,28 \%$ e $+15,96 \%$ e de $\delta^{13} \mathrm{C}$ entre $+0,13 \%$ e e $+0,67 \%$, mostrando uma menor variação isotópica. Tais composições isotópicas definem uma tendência também covariante semelhante à caracterizada para a dolomita III, porém com uma maior concentração dos valores.

\section{COMPOSIÇÃO ISOTÓPICA DE OXIGÊNIO DOS} FLUIDOS HIDROTERMAIS Os valores de $\delta^{18} \mathrm{O}_{\mathrm{H} 20}$ para o fluido em equilíbrio com dolomita hidrotermal (III e IV) foram calculados a partir da equação de fracionamento isotópico entre dolomita- $\mathrm{H}_{2} \mathrm{O}$ de Zheng (1999). O valor de temperatura utilizado nos cálculos $\left(200{ }^{\circ} \mathrm{C}\right)$ é condizente com aqueles obtidos por Cunha (1999) a partir de estudos de inclusões fluidas em quartzo e esfalerita do depósito de Morro Agudo.

A composição isotópica de oxigênio dos fluidos em equilíbrio com dolomita III, a $200{ }^{\circ} \mathrm{C}$, varia de $+5,5 \%$ a $+12,7 \%$. Menor variação dos valores de $\delta^{18} \mathrm{O}_{\mathrm{H} 2 \mathrm{O}}$ foi estimada para a dolomita IV $(+5,9 \%$ a 
Tabela 1 - Amostras e gerações de dolomita do depósito de Morro Agudo selecionadas para a análise de isótopos estáveis de carbono e oxigênio.

\begin{tabular}{|c|c|c|c|c|}
\hline Amostra & Descrição da amostra & Mineral & Tipo & Modo de Ocorrência \\
\hline IE 03 & Dolarenito mineralizado & Dolomita & I & Matriz micrítica de dolarenito mineralizado \\
\hline IE 17 & Brecha dolomítica & Dolomita & I & Clasto micrítico \\
\hline IE 21 & $\begin{array}{l}\text { Dolarenito não } \\
\text { mineralizado }\end{array}$ & Dolomita & I & Matriz micrítica de dolarenito sem substituição \\
\hline IE 24 & Brecha dolomítica & Dolomita & I & Dolomita micrítica parcialmente preservada em rocha silicificada. \\
\hline IE 25 & Brecha dolomítica & Dolomita & I & Matriz micrítica sem evidências de mineralização \\
\hline IE 28 & Brecha dolomítica & Dolomita & $\mathrm{IIb}$ & Possíveis pseudomorfos de sulfatos evaporíticos \\
\hline IE 07 & Brecha mineralizada & Dolomita & III & Dolomita esparítica associada a esfalerita \\
\hline IE 08 & Dolarenito mineralizado & Dolomita & III & Dolomita esparítica com pouca esfalerita associada \\
\hline IE 10 & Dolarenito mineralizado & Dolomita & III & Dolomita esparítica associada a pirita e calcedônia \\
\hline IE 11 & Dolarenito mineralizado & Dolomita & III & Dolomita esparítica associada a pirita e calcedônia \\
\hline IE 19 & Brecha dolomítica & Dolomita & III & Dolomita esparítica associada a pirita \\
\hline IE 23 & Brecha dolomítica & Dolomita & III & $\begin{array}{l}\text { Dolomita esparítica sem sulfetos associados em vênulas cortando o } \\
\text { dolomito silicificado }\end{array}$ \\
\hline IE 26 & Brecha dolomítica & Dolomita & III & Dolomita esparítica sem sulfetos associados _. _ . . . \\
\hline IE 31 & Dolarenito mineralizado & Dolomita & III & $\begin{array}{l}\text { Dolomita esparítica em veio acompanhando a laminação original. } \\
\text { Associada a esfalerita fina }\end{array}$ \\
\hline IE 33 & Dolarenito mineralizado & Dolomita & III & Dolomita esparítica associada a esfalerita fina \\
\hline IE 37 & Dolomito do Corpo $\mathrm{N}$ & Dolomita & III & Dolomita esparítica associada a pirita próxima do minério (corpo N) \\
\hline IE 04 & Dolarenito mineralizado & Dolomita & III & Dolomita esparítica associada a galena \\
\hline IE 01 & Dolarenito mineralizado & Dolomita & IV & Dolomita esparítica muito grossa associada a esfalerita grossa e pirita \\
\hline IE 02 & Dolarenito mineralizado & Dolomita & IV & Dolomita esparítica muito grossa associada a galena grossa \\
\hline IE 05 & Dolarenito mineralizado & Dolomita & IV & $\begin{array}{l}\text { Dolomita esparítica muito grossa associada a esfalerita. Apresenta textura } \\
\text { em zebra }\end{array}$ \\
\hline IE 06 & Dolarenito mineralizado & Dolomita & IV & Dolomita esparítica muito grossa associada a galena, cortada por pirita \\
\hline IE12 & Brecha mineralizada & Dolomita & IV & Dolomita esparítica muito grossa ocorrendo em brecha, associada a pirita \\
\hline IE 14 & Brecha mineralizada & Dolomita & IV & Dolomita esparítica muito grossa associada a pirita \\
\hline IE 15 & Brecha mineralizada & Dolomita & IV & Dolomita esparítica muito grossa associada a pirita. Presença de estilólitos \\
\hline IE 22 & $\begin{array}{l}\text { Dolarenito não } \\
\text { mineralizado }\end{array}$ & Dolomita & IV & Dolomita esparítica muito grossa associada a pirita e esfalerita \\
\hline
\end{tabular}

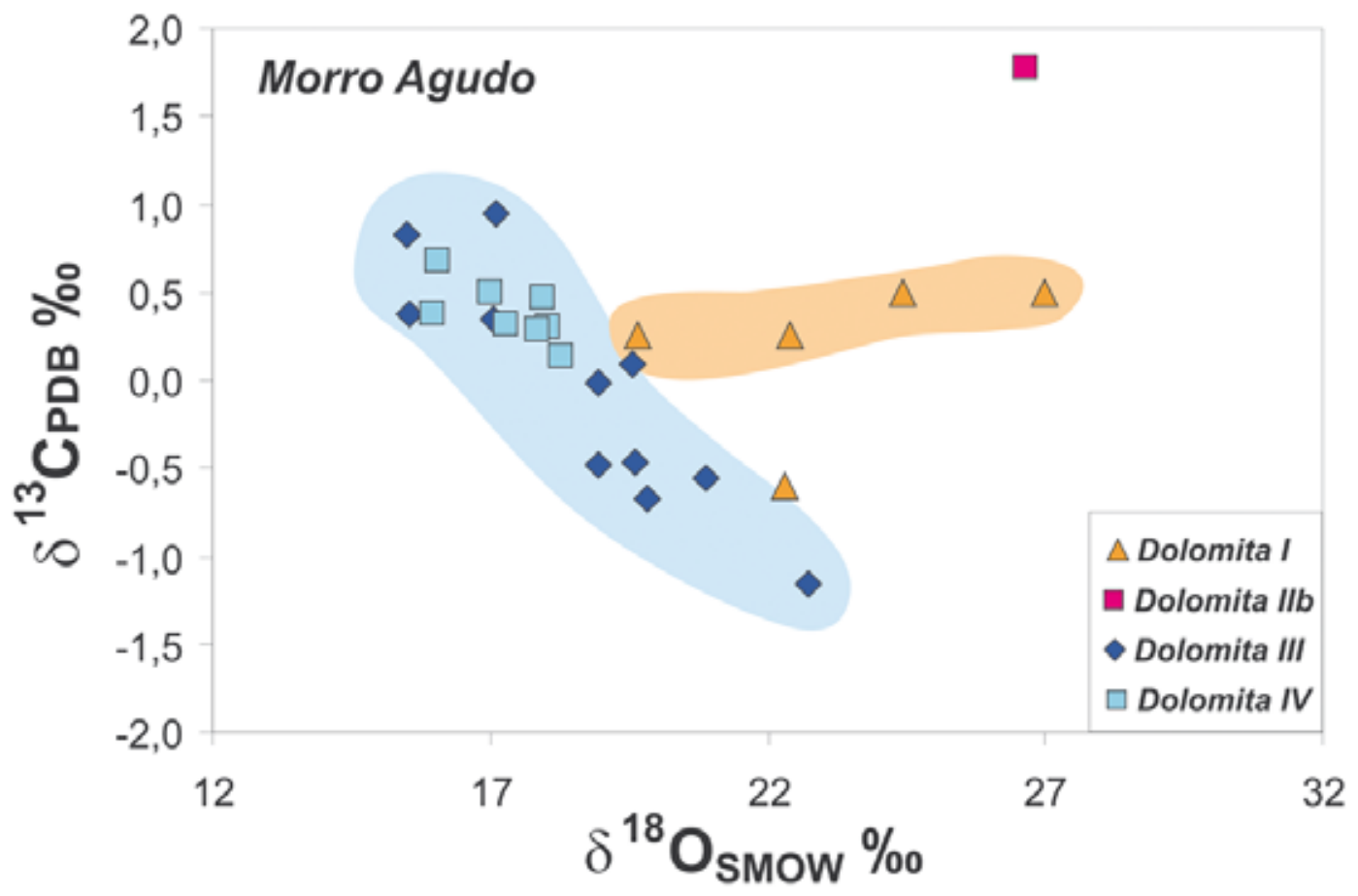

Figura 6 - Composição isotópica de carbono e oxigênio em dolomita do depósito de Morro Agudo. 
Tabela 2 - Valores de $\delta^{13} C_{P D B}, \delta^{18} O_{P D B}$ e $\delta^{18} O_{S M O W}$ para dolomita do depósito de Morro Agudo e valores calculados de $\delta^{18} O_{H 2 O}$ para fluido em equilibrio com dolomita hidrotermal (III e IV), a partir da equação de fracionamento isotópico entre dolomita- $\mathrm{H}_{2} \mathrm{O}$ de Zheng (1999) a $200^{\circ} \mathrm{C}$.

\begin{tabular}{|c|c|c|c|c|c|c|c|}
\hline \multirow{2}{*}{ Amostra } & \multirow{2}{*}{ Mineral } & \multirow{2}{*}{ Tipo } & \multirow{2}{*}{$\delta^{13} \mathrm{C}_{\mathrm{PDB}} \%$} & \multirow{2}{*}{$\delta^{18} \mathrm{O}_{\mathrm{PDB}} \%$} & \multirow{2}{*}{$\delta^{18} \mathrm{O}_{\text {SMOW }} \%$} & \multicolumn{2}{|c|}{$\delta^{18} \mathrm{O}_{\mathrm{H} 2 \mathrm{O}} \mathrm{SMOW} \%$} \\
\hline & & & & & & 150 & 200 \\
\hline IE 03 & Dolomita & I & 0,25 & $-10,88$ & 19,65 & - & - \\
\hline IE 17 & Dolomita & I & 0,49 & $-3,77$ & 26,97 & - & - \\
\hline IE 21 & Dolomita & I & 0,25 & $-8,20$ & 22,40 & - & - \\
\hline IE 24 & Dolomita & I & $-0,60$ & $-8,31$ & 22,29 & - & - \\
\hline IE 25 & Dolomita & I & 0,49 & $-6,22$ & 24,45 & - & - \\
\hline IE 28 & Dolomita & $\mathrm{IIb}$ & 1,78 & $-4,07$ & 26,66 & - & - \\
\hline IE 07 & Dolomita & III & 0,09 & $-10,95$ & 19,57 & 6,17 & 9,74 \\
\hline IE 08 & Dolomita & III & $-0,47$ & $-10,93$ & 19,59 & 6,19 & 9,76 \\
\hline IE 10 & Dolomita & III & 0,38 & $-14,87$ & 15,53 & 2,13 & 5,7 \\
\hline IE 11 & Dolomita & III & 0,34 & $-13,41$ & 17,04 & 3,64 & 7,21 \\
\hline IE 19 & Dolomita & III & 0,82 & $-14,88$ & 15,52 & 2,12 & 5,69 \\
\hline IE 23 & Dolomita & III & $-0,55$ & $-9,69$ & 20,87 & 7,47 & 11,04 \\
\hline IE 26 & Dolomita & III & $-0,01$ & $-11,55$ & 18,96 & 5,56 & 9,13 \\
\hline IE 31 & Dolomita & III & 0,95 & $-13,33$ & 17,12 & 3,72 & 7,29 \\
\hline IE 33 & Dolomita & III & $-0,48$ & $-11,53$ & 18,97 & 5,57 & 9,14 \\
\hline IE 37 & Dolomita & III & $-1,16$ & $-7,87$ & 22,75 & 9,35 & 12,92 \\
\hline IE 04 & Dolomita & III & $-0,68$ & $-10,68$ & 19,85 & 6,45 & 10,02 \\
\hline IE 01 & Dolomita & IV & 0,67 & $-14,36$ & 16,06 & 2,66 & 6,23 \\
\hline IE 02 & Dolomita & IV & 0,30 & $-12,41$ & 18,06 & 4,66 & 8,23 \\
\hline IE 05 & Dolomita & IV & 0,49 & $-13,44$ & 17,01 & 3,61 & 7,18 \\
\hline IE 06 & Dolomita & IV & 0,46 & $-12,51$ & 17,97 & 4,57 & 8,14 \\
\hline IE12 & Dolomita & IV & 0,28 & $-12,63$ & 17,84 & 4,44 & 8,01 \\
\hline IE 14 & Dolomita & IV & 0,38 & $-14,46$ & 15,96 & 2,56 & 6,13 \\
\hline IE 15 & Dolomita & IV & 0,32 & $-13,18$ & 17,28 & 3,88 & 7,45 \\
\hline IE 22 & Dolomita & IV & 0,13 & $-12,21$ & 18,28 & 4,88 & 8,45 \\
\hline
\end{tabular}

$+9,8 \%$ em $200{ }^{\circ} \mathrm{C}$; Fig. 7$)$.

\section{DISCUSSÕES}

\section{Natureza das rochas hospedeiras}

As rochas hospedeiras do depósito de Morro Agudo apresentam texturas sedimentares e diagenéticas bem preservadas. Incluem unidades clásticas de composição essencialmente dolomítica, tais como as brechas basais (floatstones e rudstones) que apresentam granodecrescência ascendente, brechas doloareníticas e dolarenitos (wackestones, packstones e grainstones).

A natureza dos intraclastos (dolomitos laminados e estromatolíticos) sugere que as brechas foram formadas em ambientes de frentes de recife (brechas de encosta ou talude) sendo compostas principalmente por material do próprio recife, como descrito por Collinson $\&$ Thompson (1989). Clastos de brechas sugerem recorrência dos episódios de brechação.

A natureza dolomítica dos clastos sugere que a dolomitização foi um processo precoce, possivelmente sin-sedimentar, como tem sido descrito para rochas carbonáticas em ambiente de recife (Tucker 2001). Comumente, os clastos apresentam evidências de cimentação por dolomita esparítica anterior à fragmentação da rocha, indicando que, ao menos em parte, tais rochas fo- ram submetidas à diagênese antes de sua fragmentação.

A presença de intraclastos de dolomitos estromatolíticos no dolarenito sugere ambiente mais distal em relação aos recifes e àquele no qual teriam sido depositadas as brechas. A presença de oólitos nos dolarenitos também indica ambiente litorâneo de águas agitadas e pouco profundas.

A unidade argilo-dolomítica (filitos grafitosos) evidencia um ambiente mais anóxico. Para sua deposição seria necessário um ambiente calmo, o que sugere que a deposição dessa unidade tenha ocorrido em períodos de transgressão do nível do mar ou, alternativamente, em ambiente lagunar mais restrito.

A história diagenética das rochas carbonáticas incluiu a substituição inicial do micrito de composição calcítica pela primeira geração de dolomita micrítica (I) e o neomorfismo, que resultou na textura microesparítica observada principalmente na matriz de dolarenitos e brechas. A cimentação inicial da rocha incluiu cimentação fibrosa, atribuída à diagênese marinha, observada raramente em dolomitos estromatolíticos. Cimentação esparítica nas brechas e preenchimentos de cavidades (vugs) por dolomita esparítica também foram comumente observados nessas rochas.

A presença de estilólitos indica que as rochas 


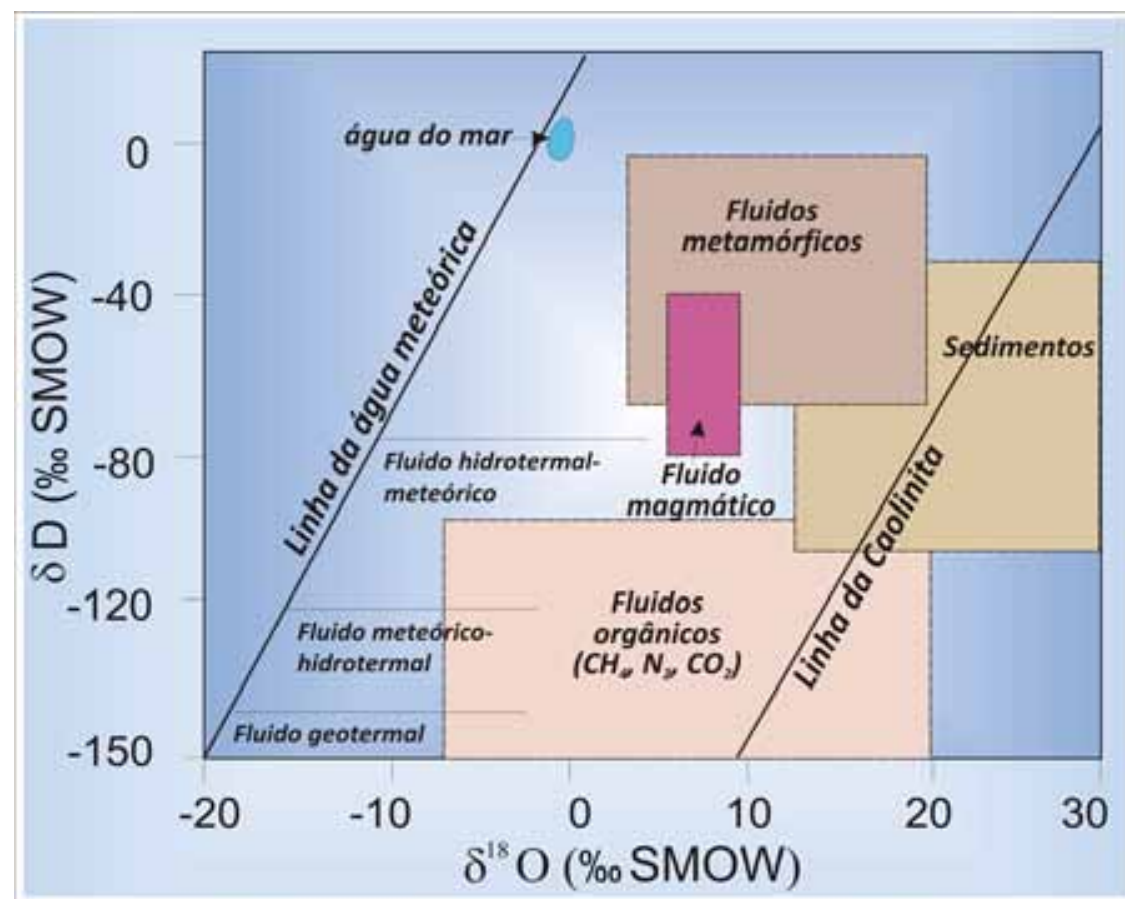

$200{ }^{\circ} \mathrm{C}$

\section{Dolomita III Dolomita IV}

Figura 7 - Composições isotópicas de oxigênio calculadas para o fluido em equilíbrio com dolomita do depósito de Morro Agudo, a $200^{\circ} \mathrm{C}$, usando a equação de fracionamento isotópico de Zheng (1999) e comparação com principais reservatórios de fluidos hidrotermais (Taylor 1974).

foram submetidas à compressão e dissolução, muito comuns durante a compactação (diagênese de soterramento). Silicificação, representada por substituição da rocha por calcedônia, foi observada tanto nas brechas como nos dolarenitos. A relação das zonas silicificadas com grandes quantidades de pirita observadas em algumas amostras pode sugerir que a silicificação representa alteração hidrotermal inicial associada à sulfetação.

Mineralização de $\mathbf{Z n - P b}$ Foram reconhecidos três episódios de mineralização no depósito de Morro Agudo: (1) substituição da matriz das brechas por calcedônia, além de esfalerita muito fina a fina e outros sulfetos, preservando na maioria dos casos as partículas carbonáticas micríticas e originando os dolarenitos mineralizados, (2) preenchimento de espaços vazios por esfalerita fina a grossa, calcedônia, quartzo, pirita e galena nos veios e cavidades maiores que geralmente acompanham a direção dos estilólitos, e (3) formação de veios e vênulas tardias com sulfetos que cortam os veios do segundo episódio e relacionam-se a microfraturas e episódios de cataclase.

O primeiro episódio resulta no minério de mais alto teor da Mina de Morro Agudo, comumente associado ao Corpo JKL. Nas brechas do Corpo GHI, a esfalerita fina e, subordinadamente, galena, substitui apenas al- guns clastos estromatolíticos ao longo de sua laminação.

A substituição das rochas hospedeiras, relacionado com interação com fluidos hidrotermais, parece ter sido controlado principalmente por sua porosidade e permeabilidade, que seriam maiores nos dolarenitos. Nas brechas, a cimentação esparítica diagenética poderia ter diminuído a permeabilidade de tais rochas. Embora esse processo possa ter se iniciado ainda durante a diagênese das rochas, sua ocorrência após a litificação é mais provável uma vez que sucedeu a cimentação esparítica.

O segundo estágio, de natureza epigenética, é representado pelo preenchimento de espaços abertos em veios e bolsões. A sequência de minerais que ocorrem preenchendo os veios e bolsões nas brechas e dolarenitos sugere que a dolomita esparítica, o quartzo e a calcedônia seriam os primeiros minerais a depositaremse a partir do fluido hidrotermal, seguidos por marcassita, pirita, esfalerita de granulometria fina, esfalerita de granulometria média e da galena, mais tardia.

A presença de marcassita, metaestável em relação à pirita, na associação de minério seria condizente com baixas temperaturas de deposição $\left(<157^{\circ} \mathrm{C}\right)$, assim como com condições de $\mathrm{pH}<5$ (Benning et al. 2000). A inversão de marcassita para pirita, indicada pelos pseudomorfos de pirita com hábito tabular, poderia ser resultado do aumento de $\mathrm{pH}$ dos fluidos devido ao tamponamento rela- 
cionado a reações com as rochas carbonáticas ou mesmo a aumento de temperatura do sistema hidrotermal.

As texturas observadas nos bolsões e veios, tais como texturas coloformes e rítmicas, podem sugerir rápida deposição dos sulfetos. A presença de zoneamentos em esfalerita, com bordas mais ricas em ferro, indicam mudança na composição química e/ou nos parâmetros físico-químicos dos fluidos hidrotermais.

Outras fases minerais, tais como barita e fluorita, além de hidrocarbonetos sólidos, comumente associam-se a esse estágio de mineralização. A associação entre betume, dolomita hidrotermal e sulfetos observada em Morro Agudo é similar à descrita em inúmeros depósitos do tipo Mississippi Valley em outras províncias (Leach \& Sangster 1993). No depósito de Polaris, no Canadá, de forma análoga ao observado em Morro Agudo, a presença de betume em preenchimentos de espaços abertos associado a sulfetos indica que sua formação foi contemporânea à mineralização (Selby et al. 2005). Isso indicaria que a matéria orgânica foi submetida à evolução termal sincrônica e relacionada à gênese das mineralizações de $\mathrm{Zn}-\mathrm{Pb}$.

A presença de matéria orgânica e hidrocarbonetos em depósitos do tipo Mississippi Valle tem sido considerada como importante para a deposição dos sulfetos, seja por intermediar a redução termoquímica de sulfatos marinhos, seja por permitir a liberação de metais e enxofre adsorvidos durante a pirólise responsável pela formação de betume a partir de hidrocarbonetos líquidos (Leach \& Sangster 1993).

No Corpo N, embora a mineralização tenha sido considerada por Misi et al. (2005) como sendo singenética ou sin-diagenética, o minério também apresenta algumas características epigenéticas, tais como a granulometria média a grossa dos sulfetos que ocorrem preenchendo veios e cavidades e sua associação com dolomita hidrotermal e zonas de silicificação. Localmente, a orientação de vênulas sugere também associação com o terceiro episódio de mineralização.

Alteração hidrotermal e fluidos hidrotermais Os resultados obtidos no estudo de isótopos estáveis de oxigênio e carbono fornecem informações relativas às rochas hospedeiras e aos fluidos hidrotermais.

Os valores de $\delta^{18} \mathrm{O}$ em minerais carbonáticos variam principalmente em função da temperatura, composição isotópica e salinidade dos fluidos a partir dos quais se precipitaram. A diminuição da temperatura dos fluidos causa aumento dos valores de $\delta^{18} \mathrm{O}$, assim como a hipersalinidade ocasionada pela evaporação. Os valores de $\delta^{13} \mathrm{C}$ podem apresentar variações relacionadas à gênese do metano e à oxidação de matéria orgânica. Os microorganismos, em seus processos metabólicos, absorvem e fixam preferencialmente o ${ }^{12} \mathrm{C}$, o que provoca o aumento da concentração de ${ }^{13} \mathrm{C}$ nas rochas carbonáticas, elevando os valores de $\delta^{13} \mathrm{C}$. Entretanto, quando ocorre a oxidação da matéria orgânica, $\mathrm{CO}_{2}$ é liberado enriquecendo o ambiente de ${ }^{12} \mathrm{C}$, provocando a diminuição dos valores de $\delta^{13} \mathrm{C}$ (Taylor 1974).

De forma geral, as gerações de dolomita clas- sificadas como do tipo I e IIb apresentaram valores de $\delta^{18} \mathrm{O}$ mais elevados do que os obtidos para as gerações III e IV. Embora tenham sido analisadas as composições isotópicas de fases minerais, considera-se que a dolomita micrítica (I) que constitui a matriz de rochas não hidrotermalizadas/mineralizadas, apresente composição isotópica próxima à da rocha hospedeira. De fato, sua composição isotópica assemelha-se a dos dolomitos hospedeiros dos outros depósitos da Faixa Vazante-Paracatu (Monteiro 1997, 2002, Monteiro et al. 2006, 2007). Entretanto, a significativa variação dos $\delta^{18} \mathrm{O}$ da dolomita I sugere que mesmo as amostras nas quais não foram observadas mudanças texturais podem ter interagido com fluidos hidrotermais. Como os fluidos, em geral, são empobrecidos em ${ }^{18} \mathrm{O}$ em relação às rochas dolomíticas, tal interação pode resultar na diminuição dos valores de $\delta^{18} \mathrm{O}$ da dolomita I. Sistematicamente observa-se em todos os depósitos da faixa também diminuição dos valores de $\delta^{13} \mathrm{C}$ em dolomitos hidrotermalizados (Monteiro et al., 2007), o que pode sugerir que os valores mais altos de $\delta^{13} \mathrm{C}(+0,25$ a $+0,49 \%)$ sejam mais próximos da composição isotópica inicial das rochas hospedeiras do depósito de Morro Agudo preservadas da alteração hidrotermal, refletindo sua assinatura marinha.

A dolomita classificada como do tipo IIb, além de apresentar elevado valor de $\delta^{18} \mathrm{O}$ (indicando sua baixa temperatura de deposição e/ou condições evaporíticas), apresentou também maior valor de $\delta^{13} \mathrm{C}(+1,78 \%)$, o que pode indicar uma menor interação com os fluidos mineralizantes que teriam sua composição isotópica alterada ao passarem pela unidade argilo-dolomítica.

A covariância isotópica assim como as composições isotópicas das gerações de dolomita hidrotermais de Morro Agudo, especialmente a dolomita III, poderiam refletir uma fonte de carbono empobrecida em ${ }^{13} \mathrm{C}$, uma vez que seus valores de $\delta^{13} \mathrm{C}$ são menores que os caracterizados para os dolomitos hospedeiros inalterados. Como o menor valor de $\delta^{13} \mathrm{C}$ refere-se à amostra do Corpo N, que ocorre interdigitado aos filitos carbonosos, é possível supor que fluidos descendentes, que percolaram essa unidade, interagiram com matéria orgânica presente nos folhelhos, contribuindo para o sistema hidrotermal. Os valores negativos de $\delta^{13} \mathrm{C}$ associados à dolomita hidrotermal podem resultar, dessa forma, oxidação da matéria orgânica durante a redução termoquímica de sulfatos.

Os demais depósitos sulfetados da Faixa Vazante-Paracatu (Ambrósia e Fagundes) também apresentam dolomita hidrotermal com valores de $\delta^{13} \mathrm{C}<0 \%$, entretanto no depósito de Vazante, no qual o minério é silicático, a dolomita hidrotermal apresenta predominantemente valores de $\delta^{13} \mathrm{C}$ positivos (média de $+0,24 \%$, Monteiro et al. 1999). Essas diferenças podem refletir uma maior contribuição de enxofre reduzido a partir dos filitos carbonosos nos depósitos sulfetados. Como na área do depósito de Vazante não são conhecidas unidades de filitos carbonosos acima dos dolomitos hospedeiros, a ausência dessa unidade pode ter contribuído para que a mineralização em Vazante seja willemítica e não sulfetada, como em Morro Agudo. 
O maior valor de $\delta^{18} \mathrm{O}$ da dolomita do Corpo $\mathrm{N}$ poderia refletir tanto fluidos hidrotermais enriquecidos em ${ }^{18} \mathrm{O}\left(>\delta^{18} \mathrm{O}_{\mathrm{H} 2 \mathrm{O}}\right)$ como menores temperaturas desses fluidos. De forma análoga, a tendência de covariância isotópica da dolomita hidrotermal de Morro Agudo poderia ser associada a mistura de fluidos com diferentes valores de $\delta^{18} \mathrm{O}_{\mathrm{H} 2 \mathrm{O}}$ ou resfriamento dos fluidos hidrotermais devido à interação com as rochas hospedeiras, mais frias.

As composições isotópicas do fluido em equilíbrio com a dolomita hidrotermal IV $\left(\delta^{18} \mathrm{O}_{\mathrm{H} 2 \mathrm{O}}=+5,9\right.$ a $+9,8 \%$ ), a $200^{\circ} \mathrm{C}$, são semelhantes às estimadas a partir de minerais de ganga nos demais depósitos da Faixa Vazante-Paracatu (Monteiro et al. 2007). Isso pode sugerir a participação de fluidos bacinais ou formacionais (fluidos de origem superficial modificados pela interação com as rochas sedimentares) para a origem de todos esses depósitos. Os fluidos associados com a dolomita III apresentam um intervalo maior de valores de $\delta^{18} \mathrm{O}_{\mathrm{H} 2 \mathrm{O}}$ $(+5,5 \mathrm{a}+12,7 \%)$, que poderia refletir tanto a participação de fluidos de mais baixa temperatura como maior interação com as rochas hospedeiras.

CONCLUSÕES Os estudos realizados permitiram a interpretação dos ambientes de deposição das diferentes unidades hospedeiras das mineralizações de Morro Agudo. As brechas podem ter sido formadas em ambientes de frentes de recife e representam recorrência dos episódios de brechação, além de apresentarem evidências de início de diagênese anterior à sua fragmentação. Os dolarenitos também estão associados à retrabalhamento dos recifes, porém seriam mais distais em relação às brechas. Essas rochas registraram vários eventos de cimentação diagenética (marinha, meteórica e de soterramento), além de silicificação, interpretada como alteração hidrotermal inicial associado à sulfetação.

Foram reconhecidos no depósito três episódios de mineralização, associados com: (1) substituição da rocha hospedeira, (2) preenchimento de bolsões e veios e (3) veios e vênulas tardios associados com microfraturas e falhas essencialmente rúpteis. Todos os estágios são considerados epigenéticos, embora a associação de veios e bolsões mineralizados com estilólitos possa sugerir migração dos fluidos hidrotermais durante a compactação.

O minério do depósito de Morro Agudo é constituído por esfalerita, galena, marcassita, pirita, dolomita esparítica, quartzo com barita, fluorita e betume associados. Tal composição é muito similar à típica de depósitos de $\mathrm{Zn}-\mathrm{Pb}$ do tipo Mississippi Valley (Leach \& Sangster 1993).

Foram observadas significativas variações dos valores de $\delta^{18} \mathrm{O}$ na dolomita I, micrítica, indicando possível interação das rochas hospedeiras com os fluidos mineralizantes, mesmo quando não foram observadas mudanças texturais nas rochas.

As composições isotópicas dos fluidos em equilíbrio com dolomita hidrotermal, III e IV, sugerem participação de fluidos bacinais ou formacionais na gênese do depósito de Morro Agudo. Pelo menos em parte, tais fluidos parecem ter percolado a unidade argilo-dolomítica superior, indicando fluxo descendente dos fluidos. Assim a migração de fluidos mais superficias, frios $\left(<100{ }^{\circ} \mathrm{C}\right)$, reduzidos e ricos em enxofre no sistema hidrotermal pode ter sido controlada pela topografia e gravidade, de modo análogo ao proposto para depósitos do tipo Mississippi Valley (Garven \& Freeze 1984). A mistura desses fluidos com fluido metalífero mais quente $\left(>200{ }^{\circ} \mathrm{C}\right)$, que teria circulado pelas partes mais profundas da bacia, poderia explicar a tendência de covariância isotópica definida pela dolomita hidrotermal. Essa mistura de fluidos representaria um mecanismo eficiente de deposição do minério.

Agradecimentos Agradecemos à Votorantim Metais Zinco, em especial aos geólogos da Mina de Morro Agudo Glacir Romagna e Eldrick Esper, por permitirem o acesso à mina e aos testemunhos de sondagem, e ao Geólogo Tolentino Flávio de Oliveira, pelo auxílio em Vazante e Morro Agudo. Agradecimentos especiais também são devidos ao Prof. Dr. Alcides da Nóbrega Sial do Laboratório de Isótopos Estáveis (LABISE) da UFPE pelas análises isotópicas e ao Dr. Evandro Klein e a um revisor anônimo por contribuírem para a melhoria desse manuscrito.

\section{Referências}

Alkmim F.F. \& Marshak S. 1998. Transamazonian orogeny in the southern Sao Francisco craton region, Minas Gerais, Brazil: evidence for Paleoproterozoic Collision and collapse in the Quadrilátero Ferrífero. Precambrian Res., 90:29-58.

Almeida F.F.M de. 1967. Origem e evolução da plataforma brasileira. Rio de Janeiro, Boletim DNPM, v. 243, 36 p.

Azmy K., Veizer J., Misi A., Oliveira T.F., Sanches A.L., Dardenne M.A. 2001. Dolomitization and isotope stratigraphy of the Vazante Formation, São Francisco Basin, Brazil. Precambrian Res., 112:303-329.

Benning L., Wilkin R.T., Barnes H.L. 2000. Reaction pathways in the Fe-S system below $100^{\circ} \mathrm{C}$. Chemical Geology, 167:251.

Bez L. 1980. Evolução mineralógica e geoquímica do depósito de zinco e chumbo de Morro Agudo, Paracatu, MG. In: SBG,
Congr. Bras. Geol, 31, Anais, 3:1402- 416.

Collinson J.D. \& Thompson D.B. 1989. Sedimentary structures. London, Unwin Hyman, 207 p.

Cunha I.A. 1999. Estudos de inclusões fluidas e de isótopos de enxofre dos corpos de minério de Morro Agudo, Minas Gerais. Dissertação de Mestrado, Universidade Federal da Bahia, $105 \mathrm{p}$.

Cunha I.A., Misi A., Babinski M., Iyer S.S.S. 2007. Lead isotope constraints on the genesis of $\mathrm{Pb}-\mathrm{Zn}$ deposits in the Neoproterozoic Vazante Group, Minas Gerais, Brazil. Gondwana Research, 11:382-395.

Dardenne M.A.1979. Les minéralisations plomb-zinc du Groupe Bambui et leur contexte géologique. Tese de Doutoramento, Univ. Pierre et Marie Curie (Paris VI), 275 p.

Dardenne M.A. 2001. Lithoestratigraphic sedimentary sequences 
of the Vazante Group. In: Misi A. \& Teixeira J.B.G. (Org.) Proterozoic base metal deposits of Africa and South America. International Geological Correlation Programme 450, CNPq/ UNESCO/IUGS, p. 48-50.

Dardenne M.A. \& Freitas-Silva F.H. 1999. Pb-Zn ore deposits of Bambui and Vazante Groups in São Francisco Craton and Brasília fold belt, Brazil. In: Silva M.D.A.G. \& Misi A. (eds.) Base metal deposits of Brazil. MME/CPRM/DNPM, p.7583.

Dardenne M.A. \& Schobbenhaus C. 2000. The Metallogenesis of the South American Platform. In: Cordani U.G., Thomaz Filho A., Campos D.A. (eds.) Tectonic evolution of South America. Rio International Geological Congress, Rio de Janeiro, Abstract, 31:231-263.

Dardenne M.A., Freitas-Silva F.H., Souza J.C.F. de, Campos J.E.G. 1998. Evolução tectono-sedimentar do Grupo Vazante no contexto da Faixa de Dobramentos Brasília. In: SBG, Congr. Bras. Geol., 40, Resumos, p. 26.

Dresch R.A.C. 1987. Aspectos geoquímicos da Jazida de Morro Agudo, Paracatu, MG. In: SBGq, Congr. Bras. Geoq., 1., 1:5-7.

Dunham R.J. 1962. Classification of carbonate rocks according to depositional texture. In: Ham W.E. (ed.) Classification of carbonate rocks. American Association of Petroleum Geologists Memoir, p. 108-121.

Garven G. \& Freeze R.A. 1984. Theoretical analysis of the role of groundwater flow in the genesis of stratabound ore deposits 1: Mathematical and numerical model: American Journal of Science, 28:1075-1124.

Golyshev S.I., Padalko N.L., Pechenkin S.A. 1981. Fractionation of stable oxygen and carbon isotopes in carbonate systems. Geokmiya, 10:427-441.

Kretz R. 1983. Symbols for rock-forming minerals. American Mineralogist, 68:277-279.

Leach D.L \& Sangster D.F. 1993. Mississippi Valley-type LeadZinc deposits. In: Kirkhan R.V., Sinclair W.D, Thorpe R.I., Duke J.M. (eds.) Mineral Deposit Modeling. Geological Association of Canada, Special Paper, 40:289-14.

Madalosso A. \& Valle C.R.O. 1978. Considerações sobre a estratigrafia e sedimentologia do Grupo Bambuí na Região de Paracatu, Morro Agudo (MG). In: SBG, Congr. Bras. Geol., 30, Anais, 2: 622 - 631 .

Madalosso A. 1980. Aspectos da diagênese dos carbonatos do Grupo Bambuí na Região de Paracatú (MG). In: SBG, Congr. Bras. Geol., 31, Anais, 4:2069-2081.

Misi A. 2001. Estratigrafia isotópica das seqüências do Supergrupo São Francisco, coberturas neoproterozóicas do Cráton do São Francisco. Idades e correlações. In: Pinto C.P. \& Martins-Neto M.A. (eds.) Bacia do São Francisco: Geologia e Recursos Minerais. SBG/MG, p. 67-92.

Misi A., Iyer S.S.S., Coelho C.E.S., Tassinari C.C.G., Franca-Rocha W.J.S., Cunha I.A., Gomes A.S.R., Oliveira T.F., Teixeira J.B.G., Conceição Filho V.M. 2005. Sediment hosted lead- zinc deposits of the Neoproterozoic Bambuí Group and correlative sequences, São Francisco Craton, Brazil: A review and a possible metallogenetic evolution model. Ore Geology Reviews, 26:263-304.

Misi A., Iyer S.S., Kyle J.R., Coelho C.E.S., Franca-Rocha W.J.S., Gomes A.S.R., Cunha I.A., Carvalho I.G. 1999. Geological and isotopic constraints on the metallogenic evolution of the Proterozoic sediment-hosted Pb-Zn (Ag) deposits of Brazil. Gondwana Research, 2:47-65.

Monteiro L.V.S. 1997. Contribuição à gênese das mineralizações de zinco da Mina de Vazante, MG. Dissertação de Mestrado, Instituto de Geociências, Universidade de São Paulo, 159p.

Monteiro L.V.S. 2002. Modelamento metalogenético dos depósitos de zinco de Vazante, Fagundes e Ambrósia, associados ao Grupo Vazante, Minas Gerais. Tese de Doutoramento, Instituto de Geociências, Universidade de São Paulo, 317 p.

Monteiro L.V.S., Bettencourt J.S., Juliani C., Oliveira T.F. 2006. Geology, petrography, and mineral chemistry of the Vazante non-sulfide and Ambrósia and Fagundes sulfide-rich carbonate-hosted $\mathrm{Zn}-(\mathrm{Pb})$ deposits, Minas Gerais, Brazil. Ore Geology Reviews, 28:201-234.

Monteiro L.V.S., Bettencourt J.S., Juliani C., Oliveira T.F. 2007. Nonsulfide and sulfide-rich zinc mineralizations in the Vazante, Ambrósia and Fagundes deposits, MG, Brazil: mass balance and stable isotope constraints on the hydrothermal alterations. Gondwana Research, 11:362-381.

Monteiro L.V.S., Bettencourt J.S., Spiro B, Graça R., Oliveira T.F. 1999. The Vazante Zinc Mine, MG, Brazil: Constraints on Fluid Evolution and Willemitic Mineralization. Exploration and Mining Geology, 8:21-42.

Oliveira T.F. 1998. As Minas de Vazante e de Morro Agudo. In: CPGG-UFBA/ADIMB, Workshop Depósitos Minerais Brasileiros de Metais Base, p. 48-57.

Romagna G. \& Costa R.R. 1988. Jazida de zinco e chumbo de Morro Agudo, Paracatu, Minas Gerais. In: Shobbenhaus C. \& Coelho C.E.S. (coords.) Principais Depósitos Minerais do Brasil. DNPM, 3:111-121.

Selby D., Creaser R.A., Dewing K., Fowler M. 2005. Evaluation of bitumen as a ${ }^{187} \mathrm{Re}-{ }^{187} \mathrm{Os}$ geochronometer for hydrocarbon maturation and migration: A test case from the Polaris MVT deposit, Canada. Earth and Planetary Science Letters 235:115.

Taylor H.P.Jr. 1974. The application of oxygen and hydrogen isotope studies to problems of hydrothermal alteration and ore deposition. Econ. Geol., 69:843-883.

Tucker M.E. 2001. Sedimentary Petrology: an Introduction to the Origin of Sedimentary Rocks. Blackwell Science, 262 p.

Zheng Y.F. 1999. Oxygen isotope fractionation in carbonate and sulfate minerals. Geochemical Journal, 33:109-126.

Manuscrito ID 16874

Submetido em 19 de fevereiro de 2010 Aceito em 20 de junho de 2010 